\title{
A VISÃO DA MORTE AO LONGO DO TEMPO
}

\author{
DEATH CONCEPTIONS THROUGH THE TIMES
}

Oswaldo Giacoia Júnior

Docente. Instituto de Filosofia e Ciências Humanas - UNICAMP

CorRESPONDÊNCIA: Departamento de Filosofia - IIFCH-UNICAMP.

giacoia@tsp.com.br

Giacoia Júnior O. A visão da morte ao longo do tempo. Medicina (Ribeirão Preto) 2005; 38(1): 13-19.

Resumo: O objetivo do presente trabalho é apresentar alguns elementos que demonstram o caráter histórico da experiência da morte, de modo a oferecer subsídios para uma reflexão sobre os diversos sentidos que a expressão simbólica da morte assume nos rituais funerários, cultos religiosos e manifestações artísticas em diferentes culturas.

Descritores: Morte. Cultura. Civilização. Ética. Religião. Medicina.

Se levarmos em consideração o parecer do filósofo alemão Arthur Schopenhauer, os animais só conhecem o presente, não tendo experiência das dimensões temporais do futuro e do passado. "Justamente por causa disso, os animais não sentem propriamente sequer a morte: eles só poderiam conhecê-la quando ela se apresenta; mas então, eles já deixaram de ser. Desse modo, a vida dos animais é um prolongado presente. Sem reflexão, eles vivem nele e nele sempre sucumbem inteiramente". ${ }^{1}$

Por causa disso, para Schopenhauer, em sua célebre visão pessimista do mundo, é a compreensão da finitude e da morte, tornada possível pela abertura temporal do ser humano, que constitui a autêntica raiz da filosofia, assim como das religiões: "O animal só conhece a morte na morte: o homem, com sua consciência, a cada hora se aproxima mais de sua morte, e isso torna a vida por vezes árdua até para aquele que ainda não reconheceu no todo da vida mesma esse caráter de permanente destruição. Principalmente por causa disso o homem tem filosofias e religiões". ${ }^{2}$

Com Schopenhauer, pode-se dizer, portanto, que a morte é o gênio inspirador, a musa da filosofia, sem ela provavelmente a humanidade não teria filosofado. Porisso, se considerado no inteiro conjunto da natureza, o homem é o único animal metafísico - e ele o é porque sua condição existencial lhe proporciona esse privilégio suspeito: o de ser o único animal que sabe por antecipação da própria morte; portanto, ao contrário de todos os outros animais, o homem sofre para além do presente, nas dimensões do passado e do futuro, e se pergunta pelo sentido de sua existência - exatamente porque sua única certeza é a de estar destinado a morrer.

Diferentes sistemas de religião e metafísica são, portanto, outras tantas respostas dadas, ao longo da história, a essa pergunta pelo sentido da vida, cujo horizonte é descortinado pela experiência da morte.

\footnotetext{
${ }^{1}$ Schopenhauer, A. Die Welt als Wille und Vorstellung II (O Mundo como Vontade e Representação II). Suplementos ao primeiro volume. In: Saemtliche Werke. Ed. Wolfgang Frhr. Von Loehneysen. Frankfurt/M: Suhrkamp, 1986, volume II, p. 83. Salvo indicação em contrário, as traduções são de minha autoria.

${ }^{2}$ Schopenhauer, A. Die Welt als Wille und Vorstellung I (O Mundo como Vontade e Representação I). Livro I. In: Saemtliche Werke. Ed. Wolfgang Frhr. Von Loehneysen. Frankfurt/M: Suhrkamp, 1986, volume I, p. 75.
} 
Se levarmos em consideração que todas as ciências especiais, como domínios circunscritos e particulares de conhecimento teórico, procedimentos metodológicos e aplicação técnica, brotaram do tronco comum da filosofia - e se esta nasce do espanto causado pelo destino incontornável da morte - então podemos medir bem a importância do tema que hoje nos reúne e a lucidez que inspirou sua escolha. No entanto, com essa introdução, meu intento era apenas prestar uma singela homenagem filosófica aos organizadores do colóquio, e não aborrecer o público com reflexões abstratas.

Sendo assim, sem abandonar totalmente o território que me é familiar, gostaria de passar diretamente para o plano mais concreto do significado histórico e social da morte, tomando por base os rituais e cerimônias funerárias, a arquitetura e o estatuário, as inscrições obtuárias, a representação pictórica que cerca a morte em diferentes civilizações. Elas oferecem um importante indicativo, como pretendo demonstrar, das maneiras diversas como as culturas se relacionam com e se posicionam em face da morte.

A esse respeito, começo por um elemento que me parece poder ser identificado como uma constante antropológica na interpretação cultural da morte na história dos povos. A morte não se refere apenas ao envelhecimento contínuo, à transitoriedade, ao declínio inexorável de todas as forças vivas. Ela evoca também um outro mundo, aterrador, "aquele da confusão, do caos, do ininteligível, onde não existe mais nada nem ninguém". ${ }^{3}$

A metáfora desse abismo, espaço vazio e indiferenciado em que a vida se precipita na escuridão das sombras, no anonimato de um caos indizível e impensável, corresponde à face obscura, aterradora, da experiência social e histórica da morte, mesmo naquelas culturas, como a hindu, por exemplo, em que o morrer é interpretado como passagem para o Absoluto, constituindo a verdade redentora e o horizonte final de significação para a vida dos homens. Nas principais civilizações da antiguidade, e a despeito de suas diferenças essenciais quanto ao significado ético-religioso da morte, esta se apresenta sempre como um limiar intransponível, uma fronteira que delimita uma região de sombras definitivamente inacessível para os vivos.
Nessa acepção, a morte é situada para além do limiar do inteiramente outro, e se a morte pode ser portadora de algum sentido, como por exemplo aquele celebrado no canto dos poetas ou nos ritos e monumentos funerários, esse sentido só pode se apresentar para os vivos: "Em sua função de memória coletiva, a epopéia não é feita para os mortos; quando ela fala deles, ou da morte, é sempre aos vivos que ela se dirige. Da morte, nela mesma, dos mortos entre os mortos, não há nada a dizer. Eles estão do outro lado de um limiar que ninguém pode transpor sem desaparecer, que nenhuma palavra pode alcançar sem perder todo sentido: mundo da noite onde reina o inaudível, ao mesmo tempo silêncio e alarido". ${ }^{4}$

Assim compreendida, a morte é vista, antes de tudo, como transpasse, travessia, ultrapassagem de fronteira, de modo que os cerimoniais fúnebres e as diferentes formas de edificações, inscrições funerárias, toda a ideologia presente nas representações pictóricas e esculturais da morte - ainda que variando de acordo com o enquadramento cultural distinto em que se inscrevem na história dos povos -, assumem a mesma função social de partes integrantes de rituais de passagem. Por meio delas, o defunto é conduzido na travessia para o outro lado, para a outra margem da existência, marcando entre os vivos a presença de um vazio, escavando uma ausência positiva que se conserva, de diferentes maneiras, na memória coletiva dos que sobreviveram. As cerimônias fúnebres são, portanto, o memorial de passagem dos que deixaram a vida e adquiriram um novo status social: o estatuto que pertence à condição de morto.

Essas formas simbólicas em que a morte se registra nos rituais e monumentos fúnebres permitem distinguir as principais figuras históricas da morte, cujo perfil singular foi traçado a partir das maneiras como diferentes sociedades assimilaram o fato bruto da morte, dando a ela uma significação cultural, e inscrevendo-a no sistema dos valores simbólicos que asseguram o funcionamento e a reprodução da ordem social.

Nesse sentido, é fundamental observar que a maneira como uma determinada sociedade se posiciona perante a morte e os seus mortos desempenha um papel decisivo na constituição e na manuten-

\footnotetext{
${ }^{3}$ Vernant, J-P. Mort grecque mort à deux faces. In: L'Individu, La Mort, L'Amour. Soi-Même et L'Autre en Grêce Ancienne. Paris: Gallimard, 1982, p. 89.

${ }^{4}$ Vernant, J-P. Mort grecque mort à deux faces. In: L'Individu, La Mort, L'Amour. Soi-Même et L'Autre en Grêce Ancienne. Paris: Gallimard, 1982, p. 86.
} 
ção de sua própria identidade coletiva, na medida em que essa integração da morte e da relação com ela constitui um dos elementos mais relevantes para a formação de uma tradição cultural comum.

A esse respeito, considero elucidativo o paralelo traçado pelo filósofo e antropólogo francês JeanPierre Vernant que põe em destaque, de um lado, a relação de todo e qualquer povo civilizado com o seu Outro, com aquilo que é considerado por ele como o diferente de si, ou como a alteridade, e, por outro lado, a relação entre os diferentes povos e essa grande alteridade, esse outro absoluto da vida, que é a morte.

"Todo grupo humano se pensa e se quer a si mesmo como um todo organizado, como uma ordem: ele se afirma como o mundo da cultura; ele é o 'civilizado'; porisso mesmo ele se define em relação ao que é outro que ele: o caos, o informe, o selvagem, o bárbaro. De maneira análoga, cada sociedade deve afrontar essa alteridade radical, essa extrema ausência de forma, esse não ser por excelência, que constitui o fenômeno da morte. É-lhe necessário, de uma maneira ou de outra, integrá-la a seu universo mental e às suas práticas institucionais. Para um grupo de homens, constituir-se um passado comum, elaborar uma memória coletiva, enraizar o presente de todos num 'outrora' desvanecido, mas do qual a rememoração se impõe, unanimemente partilhada, é também - é de início - conferir a certos personagens defuntos ou a certos aspectos desses personagens, graças a um ritual funerário apropriado, um estatuto social tal que eles permanecem, em sua condição de mortos, inscritos no coração da vida presente, que eles intervenham nela, enquanto mortos, que eles tomem a parte que lhes cabe na dominação das forças sociais de que dependem o equilíbrio da comunidade e a permanência de sua ordem". 5

Tendo isso como ponto de partida, situemos, por exemplo, o significado presente nos rituais de inumação - de sepultamento dos corpos dos defuntos -, tal como praticado pelas sociedades da antiga Mesopotâmia, considerada em muitos importantes sentidos o berço de nossa própria civilização. Os povos mesopotâmios tinham por costume enterrar os corpos dos mortos da maneira mais escrupulosa, sendo o cadáver cuidadosamente acompanhado de todas as marcas mais distintivas de sua identidade pessoal e familiar, como seus pertences, insígnias e objetos de uso, suas vestimentas e até mesmo de suas comidas prediletas.

Cuidava-se, com zelo extremo, para que nada faltasse na travessia, nada perturbasse, ou violasse, o espaço sagrado do túmulo ou mausoléu, cujo necrológio registrava a pertença do morto a uma determinada linhagem ou família, assim como a seu status e importância social. Situados junto às cidades, os cemitérios a elas pertenciam de modo essencial, demarcando como que os limites em que o mundo dos vivos se comunicava com o espaço dos mortos, tendo nele suas raízes.

"No fundo de seus sepulcros, os mortos formam assim as raízes que, dando ao grupo humano seu ponto de ancoragem no solo, lhe asseguram a estabilidade no espaço e a continuidade no tempo. Quando um conquistador pretende destruir ou reduzir à servidão uma nação inimiga, é preciso, de início, extirpar suas raízes: as tumbas, violadas, são abertas, os ossos pulverizados são dispersos ao vento. Com suas amarras rompidas, as comunidades flutuam: semelhantes a um cadáver privado de sepultura, lançado às feras, cujo espectro é condenado a vagabundear sem fim; privados de poder penetrar no reino dos mortos, eles são abandonados à errância, à marginalidade, ao caos. $\mathrm{Na}$ ótica mesopotâmia, uma sociedade cortada de seus mortos não tem mais lugar no tabuleiro de xadrez da extensão terrestre. Com suas raízes, ela perde sua estabilidade, sua consistência, sua coesão". ${ }^{6}$

No interior dessas culturas ancestrais, os rituais de inumação manifestam o siginificado tanto da vida quanto da morte: para os povos mesopotâmios, o essencial consiste na administração adequada da existência na terra, no registro de sua identidade, sendo a morte uma espécie de queda, rebaixamento, diminuição da vida - ou melhor, uma condição degradada de existência, o apagamento e a sombra do que outrora era vivo.

Aqui, trata-se, antes de tudo, de uma estratégia de assimilação política da morte, de manter, demarcando as fronteiras que separam uma da outra, a continuidade do mundo da vida e do mundo da morte, implantando a morte num subterrâneo terrestre.

Exatamente no contrário disso consistia o ritual funerário dos antigos hindus: não o sepultamento, não a edificação de mausoléus ou pirâmides mortuárias,

\footnotetext{
${ }^{5}$ Vernant, J-P. Trois Idéologies de la Mort. In: L'Individu, La Mort, L'Amour. Soi-Même et L'Autre en Grêce Ancienne. Paris: Gallimard, 1982, p. 105.

${ }^{6}$ Vernant, J-P. Trois Idéologies de la Mort. In: L'Individu, La Mort, L'Amour. Soi-Même et L'Autre en Grêce Ancienne. Paris: Gallimard, 1982, p. 108.
} 
não a representação pictórica e escultural, mas a incineração crematória. $\mathrm{O}$ cadáver não era conservado com as marcas de sua identidade, personalidade e inserção social, mas completamente consumido pelo fogo, destruído até às cinzas, que eram lançadas ao vento, ou nas águas dos rios, sendo o morto despojado de todos os seus traços identitários. Imolado como vítima sacrificial, a destruição do cadáver marcava a dissolução integral da existência terrena, a purgação de todos os seus pecados, sendo a vida individual, ela própria, significada como dilaceração da unidade, conflito, delito e transgressão, que deve ser expiada pela morte.

Esta, por sua vez, é interpretada, entre os hindus, como a via de acesso ao Absoluto, ao Eterno, ao Nirvana e à paz originária: "o sábio que compreendeu que o ser individual é uma amostra, um golpe do acaso da natureza, uma configuração possível entre milhares de possíveis na história da espécie se identifica com a vida universal e se desprende de sua individualidade, encontrando por meio do conhecimento essa atitude natural que faz com que esqueçamos nossa finitude". 7

De modo que é na morte e pela morte que se coloca o verdadeiro horizonte de sentido para a vida, justamente o contrário de seu significado para as civilizações da Mesopotâmia : "As comunidades hindus bramânicas, no que a elas concerne, não buscam implantar sua permanência na terra. Elas se enraízam no além. A vida coletiva, a ordem social, estritamente ritualizadas, não têm preço senão na medida em que, desde o início, elas visam a se ultrapassar, introduzindo-se num outro plano de existência, num domínio de realidade diferente. A morte não é a interrupção da vida, nem seu enfraquecimento ou sua sombra. Ela constitui o horizonte de sentido sem o qual o curso da existência, para pessoas e para os grupos, não teria nem direção, nem sentido, nem valor. Integrar o indivíduo na comunidade, assinalar-lhe seu lugar, seu papel, seu exato status, é fixar a ordem das etapas que, aqui nesse mundo, permitem sair dele, liberar-se dele, para reencontrar o absoluto". 8

Para ilustrar, de modo eloqüente a diversidade cultural na relação com a experiência da morte, seria oportuno evocar agora o sentido do ritual funerário e da cremação entre os antigos gregos. $\mathrm{O}$ mesmo gesto cultural - a incineração - com um sentido completamente distinto da cremação entre os hindus. No caso dos gregos, as cinzas não são lançadas ao anonimato dos ventos, mas cuidadosamente guardadas com memória dos mortos, Como os hindus, os antigos gregos cremavam os corpos dos mortos, como sacrifício expiação de tudo o que era mortal e perecível, para preparar a passagem dos mortos para uma outra condição de existência - a saber, a condição social de mortos.

No entanto, em sentido totalmente oposto ao dos brâmanes hindus, o sacrifício não tinha a intenção de apagar por completo os registros mundanos do falecido, de dissolver para sempre sua identidade, fundindo-a com o Absoluto, mas de determinar dois tipos, fundamentalmente diversos, de mortos: de um lado, a morte regular, uniforme e anônima, que acomete o comum dos mortais. Esses são os cadáveres cremados coletivamente e depositados em vala comum. De outro lado, são levados à pira crematória os corpos falecidos dos grandes heróis, na cerimônia da bela morte, a morte precoce no campo de batalha - aquela cuja marca distintiva está em ser a atestação mais efetiva da virtude e da excelência.

Essa morte torna distinto, torna aristocrático e, em sentido grego, verdadeiramente imortal o morto. É somente por ela - pela prova da virtude na morte que um autêntico grego antigo se tornava um indivíduo, passava a ser alguém, cuja vida é digna de lembrança. Exemplo mais importante dessa inscrição para sempre na memória coletiva é a morte de Aquiles, tombado na flor da idade e no campo de combate mais aguerrido. Morte celebrada pela epopéia que funda a identidade helênica, a Ilíada de Homero

Aquiles, o herói, é ali descrito como o melhor dos gregos, justamente pelo rigor implacável de sua biografia, pelo radicalismo de seus feitos e façanhas, pela recusa intransigente de qualquer compromisso e acomodação, pela excelência guerreira, a única capaz de proporcionar a glória. Esse Aquiles permanece na morte eternamente jovem, na plenitude de suas forças, sua legenda sendo sempre repetida a cada declamação da Ilíada, como cimento da identidade social dos gregos.

\footnotetext{
${ }^{7}$ Dicionário de Ética e Filosofia Moral. Ed. Monique Canto-Sperber. Trad. Ana Maria Ribeiro-Althoff et allii. São Leopoldo: Editora da Unisinos, 2003; verbete Vida e Morte, volume II, p. 748s.

${ }^{8}$ Vernant, J-P. Trois Idéologies de la Mort. In: L'Individu, La Mort, L'Amour. Soi-Même et L'Autre en Grêce Ancienne. Paris: Gallimard, 1982, p. 110.
} 
Permito-me aqui insinuar que também nós, como herdeiros culturais dos antigos gregos, conservamos algum traço dessa morte heróica, dessa comprovação da excelência pela coragem diante da morte: permitome aqui evocar a lembrança da morte de Ayrton Senna que, para além de toda exploração midiática, marcou um momento na história nacional em que nos sentimos, todos nós, um pouco identificados com o herói ceifado no melhor de seus anos, mas cuja bravura o levou a ultrapassar os limites perante os quais recua, intimidada, a maioria dos mortais.

Como observa Jean-Pierre Vernant, "existir 'individualmente' para o grego é tornar-se e permanecer 'memorável': escapa-se ao anonimato, ao esquecimento, ao apagamento - à morte, portanto - pela própria morte, uma morte que, abrindo-vos o acesso ao canto glorificador, vos torna mais presente para a comunidade, em vossa condição de herói defunto, do que os vivos o são, por eles mesmos. Essa manutenção contínua no seio do grupo é assegurada principalmente pela epopéia em sua forma de poesia oral. Celebrando as proezas dos heróis de outrora, ela tem a função, para o conjunto do mundo grego, de memória coletiva"9

A esse respeito, seria oportuno contrastar as diferentes figuras simbólicas da morte, tal como elas se desenham nessas diferentes civilizações. Tomemos, em primeiro lugar, a morte dos reis entre os povos da Mesopotâmia. Os reis são figuras absolutamente singulares e especiais - intercessores situados a meio caminho entre os humanos mortais e os deuses imortais. Em virtude de sua posição social e política, a morte dos reis adquire um significado particular: eles são sepultados com honrarias, seus cadáveres sepultados em mausoléus faustosos, sua imagem conservada para sempre nas estátuas postadas em templo e palácios, como registro perene de sua origem, ascendência e de sua importância para a vida comum do povo.

Já entre os antigos hindus, a grande personalidade não é nem o rei nem o herói. O indivíduo admirável, cuja morte merece destaque e registro permanente é aquele que é capaz de negar-se a si mesmo, de apagar já em vida os traços individuais de sua existência, recusando-se a satisfazer os dois mais poderosos mananciais da vida: o desejo de conservação e de reprodução. Entre os hindus, a verdadeira virtude só pode ser encontrada entre os ascetas, os monges, os que praticam a renúncia e se tornam faquires. Seus corpos, ao contrário de todos os outros, não são cremados em sacrifício, mas enterrados, em posição de meditação. Sobre as suas covas são edificados lugares sagrados de peregrinação e memória, como uma indicação de que o verdadeiro sentido da vida consiste no depojamento do corpo e na preparação para a morte. Morte igualmente gloriosa, mas em sentido inverso da bela morte dos heróis gregos.

No caso da bela morte, entre os gregos, não é por ser a morte do rei, ou do sacerdote, ou do grande pai de família que a morte tem um significado ao mesmo tempo ético e estético, Não se trata, portanto, da demarcação de um grupo especial na comunidade dos vivos , como signo da pertença a uma linhagem, ou a um status social. Como afirma Vernant, a morte do herói é estritamente individual e individualizante, e é porisso que ela é digna de permanecer para sempre no canto imortal do poeta: "No e pelo canto épico os heróis representam os 'homens de outrora', eles constituem, para o grupo, seu 'passado'; eles formam assim as raízes em que se implanta a tradição cultural que serve de cimento ao conjunto dos helenos, onde eles e reconhecem a si mesmos porque é somente através do gesto desses personagens desaparecidos que sua própria existência social adquire sentido, valor, continuidade". ${ }^{10}$

Para nos aproximarmos um pouco mais de nossa própria identidade cultural, cabe observar que, durante boa parte da história dos judeus, assim como para a civilização cristã, de que fazemos parte, a experiência da morte foi também vivida na chave ritualística da passagem e da transposição para o além. Para os judeus - pelo menos para aqueles que acreditavam na ressurreição após a morte -, bem como para os cristãos, a morte promovia o acesso para uma outra dimensão da vida, seja de eterno sofrimento e expiação nos infernos, ou de bem aventurança no paraíso, do qual fomos expulsos pelo pecado original.

É por escrúpulo e sentimento religioso, e em expectativa da ressurreição que, durante muito tempo e quem sabe até os dias de hoje, cultivamos o hábito social de sepultar solenemente os corpos de nossos defuntos. "Em decorrência disso, a tradição cristã estabeleceu que a morte era uma espécie de sono

$\overline{9,10}$ Vernant, J-P. Mort grecque mort à deux faces. In: L'Individu, La Mort, L'Amour. Soi-Même et L'Autre en Grêce Ancienne. Paris: Gallimard, 1982, p. 83. 
profundo, mediado pela expectativa da ressurreição, quando as almas voltariam a habitar os corpos. Essa idéia introduziu uma nova percepção e poupou gerações ao longo de séculos da idéia aterradora do fim definitivo." 11

Dessa maneira, o próprio sentido de imortalidade da alma se diferencia de acordo com as diversas maneiras de integração e gestão simbólica da morte pelas diferentes civilizações. Para os antigos gregos, por exemplo, ela era, principalmente, a glória cantada de geração a geração pelos poetas, que fazia fulgurar na memória a lembrança da grande individualidade. Para os hindus, ela significava o avesso simétrico da personalidade individual, ela era, antes, o despojamento do indivíduo, o reencontro redentor com o Absoluto, no qual se abisma e dissolve tudo o que é singular e pessoal.

Para os judeus, pelo menos durante parte de sua história, e também para nós cristãos, ela significa a passagem para a vida eterna e verdadeira, preferencialmente para a vida no jardim do Éden, em eterna contemplação e presença de Deus. Nesse sentido, pode-se afirmar que "o homem cristão deveria acreditar que somente ao morrer iniciaria a verdadeira vida, assim os ritos fúnebres, o sermão e a missa faziam parte de uma educação para enfrentar a morte, ou por outra, incutir um determinado ideal de eternidade, relacionado com as maneiras de viver, de se conduzir na vida, incluindo a maneira certa de entender e aceitar a morte." 12

Ao nos aproximarmos de nossa conclusão, caberia perguntar pelo sentido que atribuímos atualmente à experiência existencial e antropológica da morte. Como é sabido, somos os herdeiros do Esclarecimento científico, esse movimento que promoveu a racionalização completa e a dessacralização integral de todas as esferas da cultura. De posse dessa herança cultural, nós temos também da morte uma vivência dessacralizada, leiga, sobretudo clínica - um modo de representação e aculturação que se desdobra praticamente apenas no resgistro biológico. Mesmo para o fundador da Psicanálise, essa modalidade de saber que elaborou uma reflexão densa e profunda sobre a vida e a morte, mesmo para Sigmund Freud, a morte foi identificada, sobretudo com uma pulsão presente no organismo, a pulsão de morte, entendida como uma espécie de atavismo ou inércia biológica - a saber, uma tendência, inscrita na essência mesma de todo ser orgânico para regredir ao estágio inorgânico de onde proveio.

Creio poder afirmar que a intuição predominante para nós - e talvez sobretudo para vocês, profissionais e futuros profissionais da saúde - é a da morte vista principalmente como uma disfunção orgânica, como óbito e falecimento - portanto como alguma coisa essencialmente negativa, como um não ser, um mal a ser tratado, justamente como aquilo que não deve acontecer e que lhes compete evitar, com todas as forças, algo a ser removido, suprimido. A essa ideologia clínica da morte pertence sua subtração do espaço social das vivências domésticas, seu ocultamento no espaço cerrado das enfermarias, a sua retirada do campo de visibilidade e audição (quase já não mais se emprega a expressão 'grito de agonia'), seu encerramento discreto e velado, na forma silenciosa da morte hospitalar. Dessa experiência está ausente aquela antiga dimensão de sentido, que fazia da morte um ritual de passagem, uma transição para o além, pranteada e exposta nas salas de visita.

Os desenvolvimentos atuais das biotecnologias transtornaram e complicaram nossas antigas formas sociais de percepção, pensamento e sentimento a respeito da relação de pertencimento mútuo entre vida e morte. Os notáveis progressos das ciências biomédicas proporcionam atualmente para a bioética um fértil campo de indagações, para as quais estamos muito longe de poder oferecer respostas amplamente compartilhadas, como, por exemplo, a pergunta pelo sentido ético da exigência humanitária, ou da decisão clínica de deixar morrer.

Ao lado disso, e num nível de complicação teórica e prática ainda mais elevado, as biotecnologias põem à disposição do fazer humano "novas possibilidades em matéria de procriação humana e animal (ex. congelamento de embriões), de fracionamento de organismos (ex. enxertos), de transformação de organismos (ex. animais transgênicos) fazendo surgir dilemas que não são mais apenas relativos ao direito de transmitir vida e/ou de suprimi-la, mas que tocam ao direito de remodelá-la, de produzir seres vivos novos,

\footnotetext{
${ }^{11}$ Fleck, E. C. D. Almas cristãs em corpos doentes - sensibilidade barroca nas reduces jesuítico-guaranis do século XVII. In: Keil, I. E Tiburi, M. O Corpo Torturado. Porto Alegre: Ed. Escritos, 2004, p. 199.

${ }^{12}$ Fleck, E. C. D. Almas cristãs em corpos doentes - sensibilidade barroca nas reduces jesuítico-guaranis do século XVII. In: Keil, I. E Tiburi, M. O Corpo Torturado. Porto Alegre: Ed. Escritos, 2004, p. 216.
} 
e até mesmo de industrializar essa produção (com o risco de marginalizar espécies naturais consideradas obsoletas). O homem já se vê na obrigação de dirigir a evolução biológica, e capaz de corrigir os defeitos de sua própria natureza." 13

Tais condições reconfiguram também, introduzindo-as num plano de sentido totalmente inédito, nossas antigas crenças e esperanças de imortalidade: eles indicam que, para nós, a arcaica representação da morte, assim como o sempre presente desejo de perpetuação da vida - a ela inevitavelmente associado -, adquire hoje um contorno inusitado, digno de ser pensado em toda sua extensão e profundidade: não mais a sobrevivência heróica na memória popular, guardada para sempre pelo canto do poeta; não mais a sobrevida dos reis magníficos, ou das grandes personagens da história política dos povos, também não mais a fusão com o Absoluto, ou a eterna bem aventurança no Paraíso, mas a sobrevida como reprodução, virtualmente infinita, de artefatos técnicos do fazer humano. E, com isso, encerro essa comunicação sem o efeito tranquilizador de uma conclusão positiva, mas abrindo para um novo horizonte de indagações urgentes: a que tipo de ética podemos e devemos recorrer para a adequada compreensão e possível solução de tais problemas?

Giacoia Junior O. Death conceptions through the times. Medicina ( Ribeirão Preto) 2005; 38: 13-19.

Abstract: The goal of this article is to present some elements that exhibit the historic aspect of the death experience, in a such a way that offers subject for a reflexion about the various meanings the symbolic expression of death assume in funereal rituals, religious cults and artistic manifestations in different cultures.

Keywords: Death. Culture. Civilization. Ethics. Religion. Medicine.

\section{REFERÊNCIAS BIBLIOGRÁFICAS}

Canto-Sperber M, ed. Dicionário de ética e filosofia moral. Verbete Vida e Morte. Trad. AM Ribeiro-Althoff et allii. São Leopoldo: Editora da Unisinos; 2003. Vol. II, p. 748s.

Keil IE, Tiburi M. O corpo torturado. Porto Alegre: Ed. Escritos; 2004.

Schopenhauer A. Die welt als wille und vorstellung I (O mundo como vontade e representação I). Livro I. In: Sämtliche werke. Frankfurt/M: Suhrkamp: Ed. Wolfgang Frhr. Von Loehneysen; 1986. Vol. I.
Schopenhauer A. Die welt als wille und vorstellung II (O mundo como vontade e representação II). In: Sämtliche Werke. Frankfurt/M: Suhrkamp: Ed. Wolfgang Frhr. Von Loehneysen; 1986. Vol. II.

Vernant J-P. L'individu, la mort, l'amour. soi-même et l'autre en Grêce ancienne. Paris: Gallimard; 1982.

\footnotetext{
${ }^{13}$ Dicionário de Ética e Filosofia Moral. Ed. Monique Canto-Sperber. Trad. Ana Maria Ribeiro-Althoff et allii. São Leopoldo: Editora da Unisinos, 2003; verbete Vida e Morte, volume II, p. 748s.
} 